Francesco Negro, Corrado Cremonini, Marco Fringuellino and Roberto Zanuttini*

\title{
An innovative composite plywood for the acoustic improvement of small closed spaces
}

DOI 10.1515/hf-2016-0122

Received July 27, 2016; accepted March 13, 2017; previously published online April 13, 2017

\begin{abstract}
Poor acoustics is a common problem in many small closed rooms such as offices or dining rooms. Sound absorbing panels used as wall or ceiling coverings can be a remedy. In the present paper, the sound absorption properties of a composite made of two plywood skins bonded to an inner honeycomb core of plywood cells, designed by the authors in a previous study, were improved by drilling the surfaces. The holes communicate with the void cells of the core, activating the Helmholtz resonance effect. The acoustic behavior of small specimens and final-size samples are described, which were also tested in a reverberation chamber and in a real dining room. The developed lightweight composite plywood achieved $\alpha_{\max } 0.90$ values (maximal sound absorption coefficients) around $400 \mathrm{~Hz}$, i.e. in the low frequency range, resulting in being well suited for various acoustic improvements.
\end{abstract}

Keywords: composite plywood, Helmholtz resonators, honeycomb core, lightweight panels, perforated panels, poplar veneer, sound absorption, wood based panel

\section{Introduction}

Small, closed offices and dining rooms are often affected by poor acoustics, particularly when very crowded (Kuttruff 2009). The human voice reflected by the surfaces of these environments generates high levels of noise and reduces the speech intelligibility. The negative effects are obvious such as high stress and low productivity (Yost 2014). Sound-absorbing materials may improve this situation, among which sound-absorbing perforated panels installed as walls and ceiling covering play an important role in absorbing the incident sound. Usually, the acoustic materials cover wide surfaces, but they can also

\footnotetext{
*Corresponding author: Roberto Zanuttini, University of Torino, DISAFA, Grugliasco (TO), Italy, e-mail: roberto.zanuttini@unito.it Francesco Negro and Corrado Cremonini: University of Torino, DISAFA, Grugliasco (TO), Italy

Marco Fringuellino: SAE Institute, Milano, Italy
}

be installed with minor extensions in specific positions, for instance, in the corners of a room (Cox and D'Antonio 2004). To be effective, they should absorb sound around the frequencies emitted by the human voice, i.e. in the low frequency range and in particular between $125 \mathrm{~Hz}$ and $1000 \mathrm{~Hz}$ (Tang and Chan 1996). The aesthetics of these materials is also relevant as their installation influences the room's appearance.

The present paper reports the development and testing of an innovative sound-absorbing composite plywood (CP), that is a lightweight sandwich panel made of two plywood skins bonded to an inner honeycomb core constituted by plywood cells. Despite its light weight, it has interesting mechanical properties in terms of the strength/ weight ratio, which is important in the transport sector (Negro et al. 2011). The present paper describes the CP behavior and its optimization for acoustic improvement.

Wood and wood-based panels absorb a limited amount of sound within the low frequency range (Bucur 2006; Smardzewski et al. 2014, 2015). This is the reason why the present research focuses on perforation of the panels aiming at conferring sound absorption properties on them through the Helmholtz resonance effect (Everest and Pohlmann 2009). A Helmholtz resonator is a system made of two communicating volumes: the smaller one is called the "neck", while the larger one is the "cavity". As for the $\mathrm{CP}$, the surface holes represent the necks, while the honeycomb cells are the cavities. When hit by sound waves, the air in the neck acts like a mass that presses the air in the cavity, which performs like a "spring". The oscillation of such mass-spring system is able to absorb high amounts of sound energy corresponding to the specific "resonance frequency". Thus perforation of lightweight $\mathrm{CP}$ activates its void cells in the honeycomb core, making them behave like cavities in the acoustic sense.

The sound absorption properties of Helmholtz resonators are mainly determined by the geometry of the system (Everest and Pohlmann 2009). Poplar (Populus spp.) wood was chosen for $\mathrm{CP}$ preparation because the elements produced from poplar are light and easy to install, and the light color is suitable for several types of finishing and surface printing. Moreover, poplar is one of the main wood species used for plywood and therefore it is easily available (Castro and Zanuttini 2008). The experimental design aimed at determining the best drilling patterns and 
testing the sound absorption properties both on small and large-scale samples according to standardized methods and also in end-use application.

\section{Materials and methods}

Panels production: The $\mathrm{CP}$ preparation was described by Negro et al. (2011) as illustrated in Figure 1. Three-layered poplar plywood panels were hot-pressed in a wavy press (a); the resulting wavy panels (b) were turned around $180^{\circ}$ over their length axis and overlaid in order to form a honeycomb block (c); the block was cut perpendicular to its height (d) to obtain honeycomb sheets of the desired thickness (e); these were laid between two poplar plywood panels and the resulting CP (f) was hot bonded by means of the same commercial urea-formaldehyde (UF) resin used for bonding the plywood panels. This is suitable for panels intended for interior environments, it has a dry residue of $63 \pm 1 \%$, a molar ratio urea/ formaldehyde of 1:1.2 and a mixture made of 100 parts of UF resin, eight of wheat flour, and eight of hardener solution $\left(25 \% \mathrm{of} \mathrm{NH}_{4} \mathrm{Cl}\right)$. The $\mathrm{CP}$ was designed to reach a final thickness of $38 \mathrm{~mm}$, resulting from an upper skin in poplar plywood of $9 \mathrm{~mm}$, a honeycomb core of $25 \mathrm{~mm}$ and a rear skin of $4 \mathrm{~mm}$. The cells of the core that are formed by two sinusoidal plywood waves bonded along a transversal symmetry axis are $45 \mathrm{~mm}$ wide and $95 \mathrm{~mm}$ long. The thickness of the upper skin was calculated to obtain the desired volumes of the holes drilled through it, while the back skin is thinner to further reduce the overall weight. The composite, with a density of $185 \mathrm{~kg} \mathrm{~m}^{3}$, falls within the category of lightweight panels (Thömen 2008). From this material 26 samples in end-use sizes were prepared: $600 \times 600 \mathrm{~mm}$ (no. 16 CP panels), $1200 \mathrm{~mm} \times 600 \mathrm{~mm}$ (no. 8), $1200 \mathrm{~mm} \times 1200 \mathrm{~mm}$ (no. 2). These dimensions were selected as

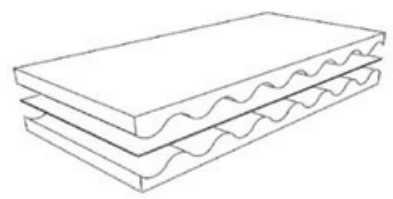

a

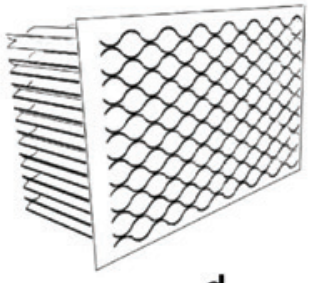

d

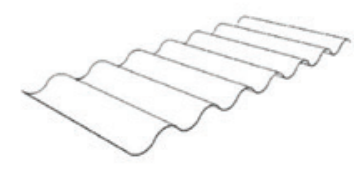

b

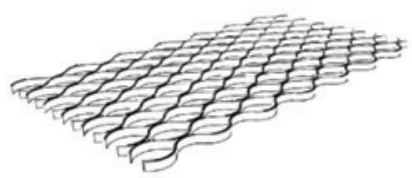

e
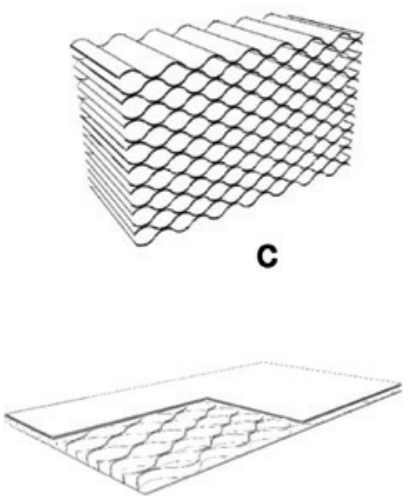

f

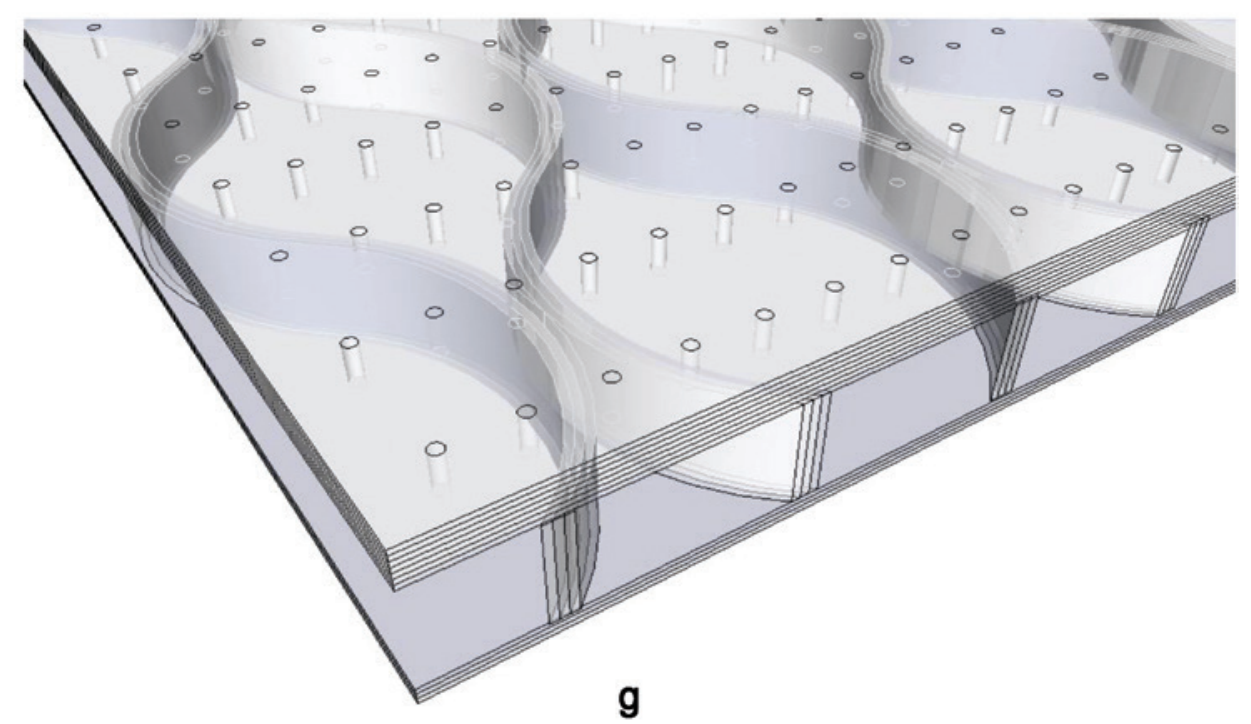

Figure 1: Outline of the production process of the composite plywood $(a-f)$ and scheme of its perforation with holes of $3 \mathrm{~mm}$ and drilling percentage of $1.41(\mathrm{~g})$.

The holes constitute the necks of the Helmholtz resonators and communicate with the honeycomb cells, which represent the cavities. 
the size of $600 \times 600 \mathrm{~mm}$ is a modulus commonly used for panels intended for ceilings and wall coverings.

Acoustic testing: The sound absorption of small specimens was tested in the impedance tube, and that of large samples in a reverberation chamber and in a regular dining room. The acoustic testing followed the design of Negro et al. (2016) with some modifications. Firstly, the sound absorption coefficient $\alpha$ (ranging from 0 , when all incident sound is reflected, to 1 , in case of complete absorption) was determined through the impedance tube method according to EN ISO 10534-2 on small specimens cut from CP. Various drilling patterns were tested in order to find the best solution concerning both the sound absorption performance and the working times required to drill the composites in end-use sizes with a CNC machine. Holes diameter was set to 3 or $5 \mathrm{~mm}$, while drilling percentages varied from 0.32 to 5.67 ; three specimens for each drilling pattern were tested.

On the basis of the impedance tube test results, CP panels in end-use sizes were drilled with a CNC machine (Figure 1g). Half of the composites produced for each size were realized with a hole diameter $(\varnothing) 3 \mathrm{~mm}$ and a half with hole $\varnothing 5 \mathrm{~mm}$; drilling percentage was always set to 1.41 . Sound absorption properties of perforated $\mathrm{CP}$ at $8 \%$ of moisture content (MC), a typical value for wood-based panels used in indoor heated environments, were determined according to EN ISO 354 in a reverberation chamber arranged with $10.4 \mathrm{~m}^{2}$ of CP.

Finally, CP panels at $8 \%$ of MC were installed on the walls in a dining room of a small medium enterprise, a typology of a closed space often affected by poor acoustics (Kang 2002). The method was selected according to EN ISO 3382, while tests and results analysis were performed according to EN ISO 354 . CP panels were installed in the dining room with a uniform distribution for a total samples surface of $14.4 \mathrm{~m}^{2}$. Beside $\alpha$, the following acoustic parameters were determined:

- $R T_{60}$ (reverberation time), which is the time needed for sound to decrease by $60 \mathrm{~dB}$;

- $\quad C_{50}$ (clarity), which is the logarithmic ratio of the early to late arriving sound energy in the impulse response; it assesses the quality of speech transfer to the listeners;

- $\quad D_{50}$ (definition), which is the energy ratio of early sound to total sound; it indicates how limpid and intelligible is the perceived speech;

- $T_{\mathrm{S}}$ (center time), which is the time of the energetic center of gravity of the squared impulse response; it is correlated to the abovementioned parameters but it is free from a specific integration limit.

\section{Results and discussion}

\section{Tests with the impedance tube}

The peak values of the sound absorption coefficients $\left(\alpha_{\max }\right)$ determined for small scale specimens by means of the impedance tube method are presented in Table 1 together with the data of holes diameters $(\varnothing)$ and
Table 1: Sound absorption peak values and relative frequencies determined through the impedance tube.

\begin{tabular}{lrrr}
\hline $\begin{array}{l}\text { Holes } \\
\text { diam. }(\mathrm{mm})\end{array}$ & $\begin{array}{r}\text { Drilling } \\
\mathbf{( \% )}\end{array}$ & $\begin{array}{r}\text { Sound abs. } \\
\text { max. }(\boldsymbol{\alpha})\end{array}$ & $\begin{array}{r}\text { Frequency } \\
\mathbf{( H z )}\end{array}$ \\
\hline 3 & 0.32 & 0.80 & 188 \\
3 & 1.41 & 0.95 & 426 \\
3 & 5.67 & 0.62 & 779 \\
5 & 0.32 & 0.89 & 156 \\
5 & 1.41 & 0.90 & 418 \\
5 & 5.67 & 0.51 & 727 \\
\hline
\end{tabular}

drilling percentages (drilling \%), such as the corresponding frequencies. The $\alpha_{\max }$ data ranged from 0.51 to 0.90 at frequencies from $188 \mathrm{~Hz}$ to $779 \mathrm{~Hz}$, i.e. within the frequency range of the human voice. Patterns with holes $\varnothing$ of 3 and $5 \mathrm{~mm}$ and 1.41 drilling \% were selected as the most interesting combinations considering both $\alpha_{\max }$ (Figure 2) and working times required to drill the CP in end-use size.

In detail, the $\mathrm{CP}$ with an appropriate surface drilling is able to absorb high amount of sound energy within frequencies ranging from $350 \mathrm{~Hz}$ to $500 \mathrm{~Hz}$, where it achieves $\alpha_{\max }$ values of 0.95 at 426 (holes $3 \mathrm{~mm} \varnothing$ ) and $\alpha_{\max }$ values of 0.90 at $418 \mathrm{~Hz}$ (holes $5 \mathrm{~mm} \varnothing$ ). The curves of $\alpha_{\max }$ could be further enlarged, despite a decrease in $\alpha_{\max }$ value, by filling the honeycomb cells with a sound absorbing material such as a thermoplastic foam (Arenas and Crocker 2010). This is feasible during the production process: for instance synthetic foams can be sprayed into the honeycomb block inside which they subsequently expand and solidify.

It is worth to note that the fundamental equation for the resonance frequency $f_{\text {res }}$ of an ideal Helmholtz resonator, commonly reported in standard textbooks on acoustical theory (e.g. Blackstock 2008; Webster and Davies 2010), is:

$$
f_{\text {res }}=\frac{c}{2 \pi} \sqrt{\frac{s_{p}}{V_{c p}}}
$$

where $c$ is the speed of sound, $s_{p}$ is the cross sectional area of the hole, $V_{c}$ is the volume of the cavity and $l_{p}$ is the length of the neck. According to Eq. 1, the absorption peak of $\mathrm{CP}$ can be shifted by varying the thickness of the honeycomb core, which corresponds to $V_{c}$, with higher thicknesses returning lower frequencies of resonance. Based on this, CP can be created with acoustic behavior centered on different and complementary frequencies, by simply varying the thickness of the honeycomb core. 


\section{Acoustic tests in the final products}

Figure 2 shows the sound absorption properties of the developed CP with $1.41 \%$ drilling, which were determined in a reverberation chamber and in a dining room, respectively. The performance declared in the technical data sheets of two drilled panels produced by an Italian manufacturer and which are available on the market is also reported. These are made of $16 \mathrm{~mm}$ thick MDF panels, perforated with holes of $3 \mathrm{~mm}$ diameter and drilling percentages of 0.6 and 1.1, respectively; their properties refer to an installation with a rear cavity of thickness $200 \mathrm{~mm}$ partially filled with a $30 \mathrm{~mm}$ thick polyester mat.
The $\alpha_{\max }$ values in reverberation chamber are 0.67 at $315 \mathrm{~Hz}$ and 0.66 at $400 \mathrm{~Hz}$, while those measured in the dining room are $0.91 \mathrm{at} 400 \mathrm{~Hz}$; from their comparison the shape of the $\alpha_{\max }$ curves recorded in the reverberation chamber appears to be cut off. Due to the testing protocol, the sound absorption in the reverberation chamber has been measured in a onethird octave and the values are only recorded in correspondence of band centers, while the values in between are not recorded. Taking into consideration the $\alpha_{\max }$ curve determined and the results found both in impedance tube and in dining room, the real peak in reverberation chamber can be estimated to ca. $\alpha_{\max }=0.85-0.90$ at $380 \mathrm{~Hz}$.
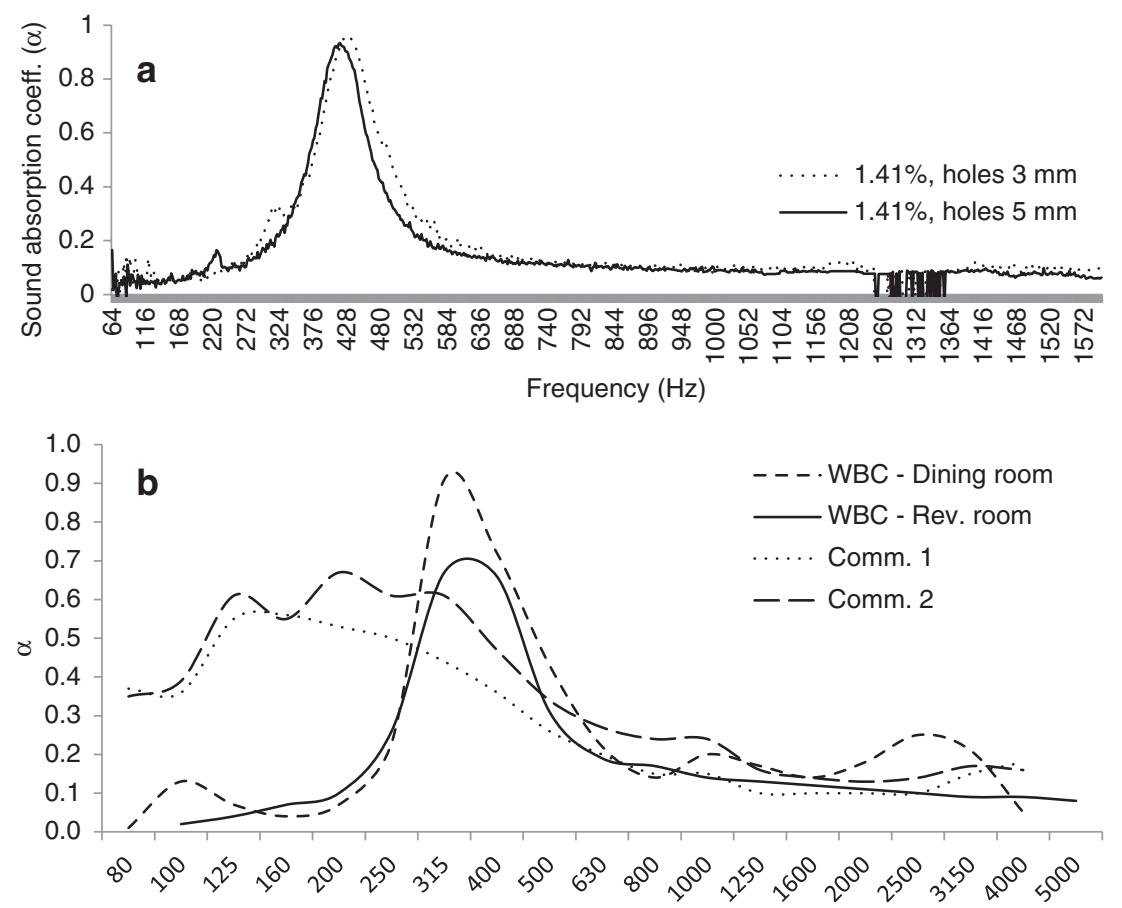

$\mathrm{Hz}$

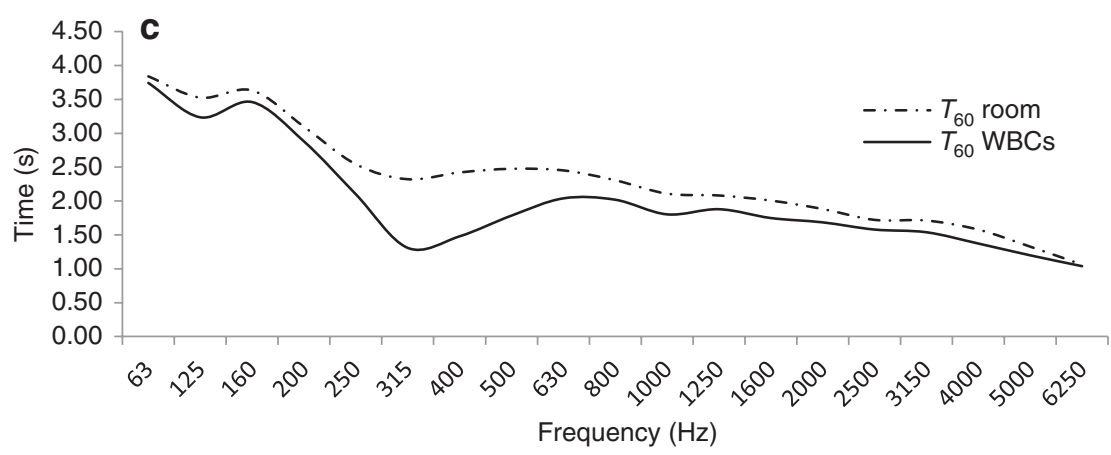

Figure 2: Acoustic behaviour of the developed CP.

Sound absorption coefficient $\alpha$ measured in the impedance tube for specimens with drilling percentage of 1.41 and holes with diameters of 3 and $5 \mathrm{~mm}$ (a). Sound absorption coefficient of the CP determined in reverberation chamber (EN ISO 354 ) and in a dining room, and absorption curves, declared by producers, of two established commercial panels (Comm. 1 and Comm. 2) available on the market (b). $R T_{60}$ measured in the dining room with and without panels (c). 
As already mentioned, a substantial broadening of the absorption curves of Helmholtz resonators, despite a decrease in $\alpha_{\max }$ value, can be reached by foam filling the core (Ginn 1978; Everest and Pohlmann 2009; Arenas and Crocker 2010). This would broaden the acoustic behavior, as for other commercial products. Anyway, the selective peak achieved by a non-filled core can represent an added value for some applications, for instance in recording studios, where the acoustic designs are aimed at correcting specific frequencies. It is remarkable, that the irregularities due to the production of end-size composites, such as the presence of some holes on the honeycomb walls instead of the void cells, did not significantly modify the acoustic performance. Results on small-scale specimens and on real sized CP panels in a reverberation chamber and a dining room showed an appreciable correspondence. As for the reverberation time $\left(R T_{60}\right)$, Figure 2 reports the values calculated for the dining room with and without panels.

A t-test was performed for comparing $R T_{60}$ measured in the dining room with and without the presence of the panels. Significant differences for $\mathrm{P}<0.01$ were found at 125, 250, 315, 400, 500, 630, 800 1000, 1250, 1600, 2000, 3150 and $4000 \mathrm{~Hz}$. In particular, an $R T_{60}$ decrease of about $40 \%$ at $315 \mathrm{~Hz}$ and $400 \mathrm{~Hz}$, where it was $1.31 \mathrm{~s}$ and $1.48 \mathrm{~s}$, respectively; both of these values are lower than $1.5 \mathrm{~s}$,

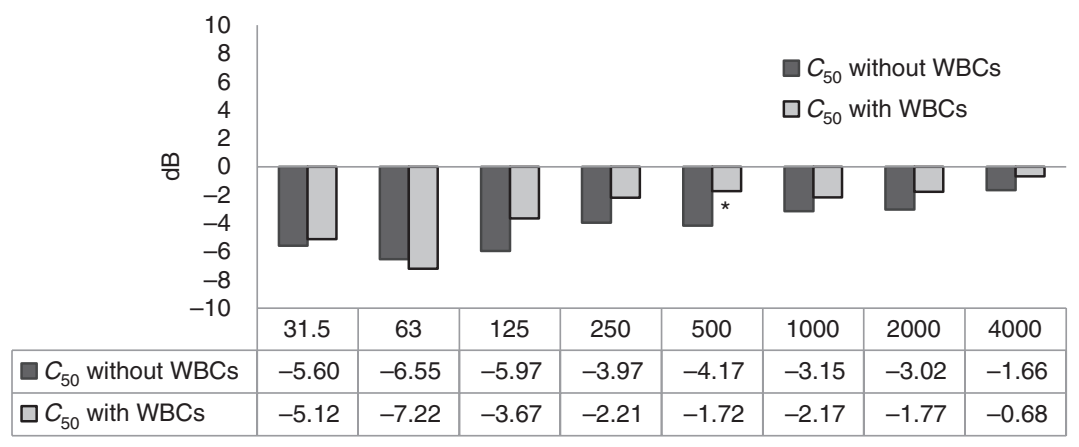

Frequency $(\mathrm{Hz})$ and $C_{50}(\mathrm{~dB})$
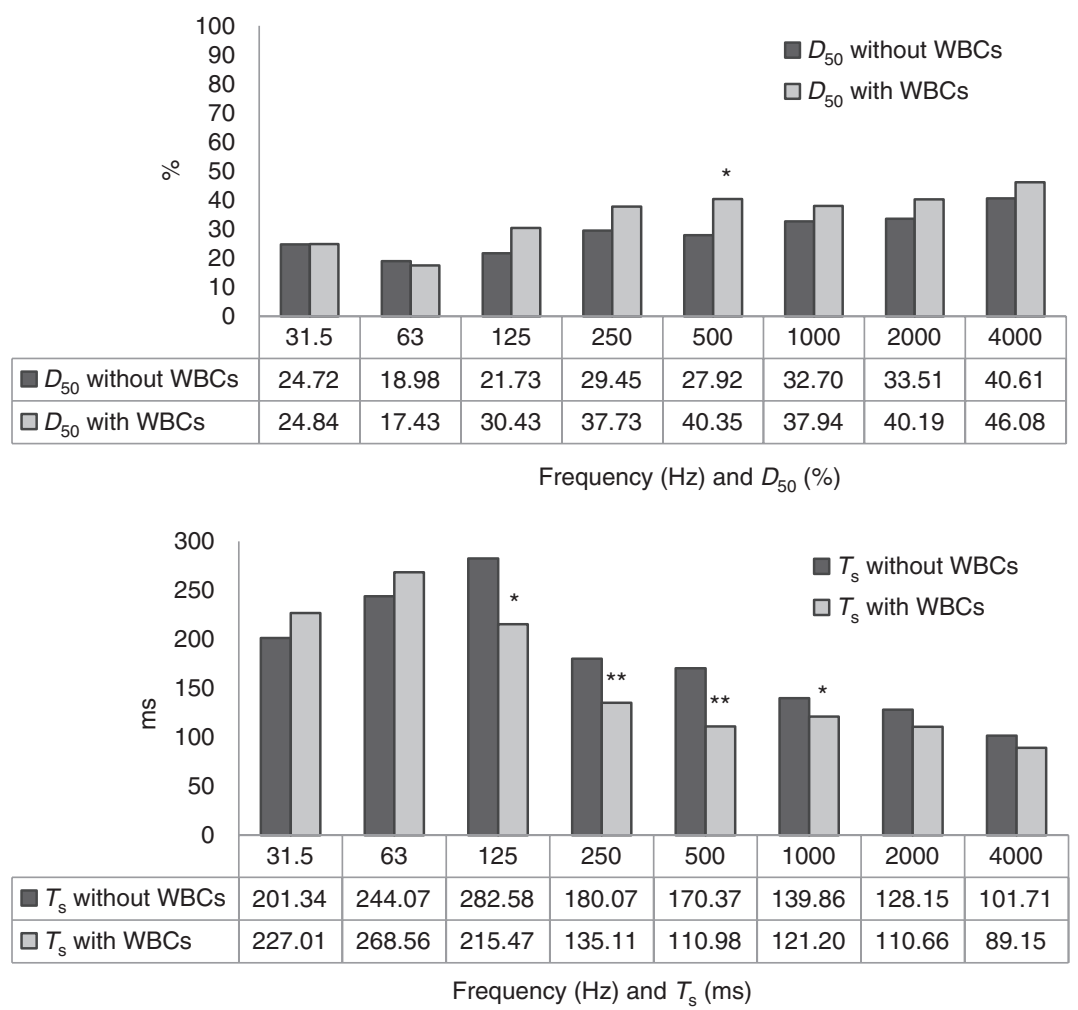

Figure 3: $C_{50}$ (top), $D_{50}$ (centre) and $T_{\mathrm{s}}$ (bottom) measured in the dining room arranged with and without panels. *Significant difference at the 0.05 level; ${ }^{\star \star}$ significant difference at the 0.01 level. 
estimated as being the threshold for optimum $R T_{60}$ in rooms intended for speech (Kuttruff 2009). Clarity $\left(C_{50}\right)$, definition $\left(D_{50}\right)$ and center time $\left(T_{\mathrm{s}}\right)$ for the room arranged with and without panels are reported in Figure 3.

The values measured in the dining room with and without panels were compared using a t-test. For $T_{s}$, significant differences for $\mathrm{P}<0.05$ or $\mathrm{P}<0.01$ were found at 125, 250, 500 and $1000 \mathrm{~Hz}$. For $C_{50}$ and $D_{50}$ significant differences for $\mathrm{P}<0.01$ were found at $500 \mathrm{~Hz}$. All of the results presented implicate an improvement of the considered parameters that were always higher than the just noticeable difference levels set by the EN ISO 3382-1. In general, these variations improved the overall clarity of sound and are particularly relevant from $250 \mathrm{~Hz}$ to $1000 \mathrm{~Hz}$ that constitutes a fundamental region of the human voice spectrum.

A complete acoustic recovery of the environment, which was not the aim of the present work, would require a specific design and the installation of a higher amount of panels: this would certainly result in even better values for $R T_{60}, C_{50}, D_{50}$, and $T_{s}$.

\section{Conclusions}

The tested composite plywood revealed $\alpha_{\max }$ values around 0.90 at $400 \mathrm{~Hz}$. The results in the reverberation chamber and in a common dining room indicated that effect of the irregularities of the end-size composites was negligible. Testing in the reverberation chamber justified the hope that the panels have a chance to enter the market with further developed products. The parameters related to the clarity of sound $\left(C_{50}, D_{50}, T_{\mathrm{s}}\right)$ were also significantly improved. Poplar plywood seems to be well suited for realizing acoustic products, which are also optically appealing. The developed composite plywood lowers the overall sound level and is able to correct specific frequencies, and thus it is well suited for acoustic improvement of small closed spaces.

Acknowledgments: The experimental activity reported in this paper was realized within the OPTISOUNDWOOD project, granted by the Piedmont Region in the framework of the EU Rural Development Plan 2007-2013, Action 124.2 "Cooperation for the development of innovative products, processes and technologies in the forest sector - Innovation in forest field".

\section{References}

Arenas, J.P., Crocker, M.J. (2010) Recent trends in porous soundabsorbing materials. Sound Vib. 44:12-17.

Blackstock, D.T. Fundamentals of Physical Acoustics. John Wiley \& Sons, Inc., New York, 2000.

Bucur, V. Acoustics of Wood. Springer-Verlag, Berlin, 2006.

Castro, G., Zanuttini, R. (2008) Poplar cultivation in Italy: history, state of the art, perspectives. In: Proceedings of the Cost Action E44 Final Conference on a European wood processing strategy, Ghent University, Milan.

Cox, T.J., D’Antonio, P. Acoustic Absorbers and Diffusers. Spon Press, New York, 2004.

EN ISO 10534-2:2001. Acoustics. Determination of sound absorption coefficient and impedance in impedance tubes. Part 2: Transfer function method. European Committee for Standardization, Brussels.

EN 354:2003. Acoustics. Measurement of sound absorption in a reverberation chamber. European Committee for Standardization, Brussels.

EN ISO 3382-1,2,3:2012. Acoustics. Measurement of room acoustic parameters. European Committee for Standardization, Brussels.

Everest, F.A., Pohlmann, K.C. Master Handbook of Acoustic - Fifth edition. McGraw Hill, New York, 2009.

Ginn K.B. Architectural Acoustics. Brüel \& Kjær, Nærum, 1978.

Kang, J. (2002) Numerical modeling of the speech intelligibility in dining spaces. Appl. Acoust. 63:1315-1333.

Negro, F., Cremonini, C., Properzi, M., Pichelin, F., Zanuttini, R. (2011) A new wood-based lightweight composite for boatbuilding. Wood Res. 56:257-266.

Negro, F., Cremonini, C., Fringuellino, M., Zanuttini, R. (2016) Development of framed poplar plywood for acoustic improvement. Wood Res. 61:121-128.

Kuttruff, H. Room Acoustics - Fifth edition. Spoon Press, Abingdon, 2009.

Smardzewski, J., Batko, W., Kamisiński, T., Flach, A., Plich, A., Dziurka, D., Mirski, R., Roszyk, E., Majewski, A. (2014) Experimental study of wood acoustic absorption characteristics. Holzforschung 68:467-476.

Smardzewski, J., Kamisiński, T., Dziurka, D., Mirski, R., Majewski, A., Flach A., Plich A. (2015) Sound absorption of wood-based materials. Holzforschung 69:431-439.

Tang, S.K., Chan, J.V.C. (1996) Some characteristics of noise in airconditioned landscaped offices. Appl. Acoust. 48:249-267.

Thömen, H. (2008) Lightweight panels for the European furniture industry: some recent developments. In: Proceedings of the COST E49 Conference: Lightweight Wood-based Composites. Production, Properties and Usage. Bled, $23^{\text {rd }}-25^{\text {th }}$ June.

Webster, E.S., Davies, C.E. (2010) The use of Helmholtz resonance for measuring the volume of liquids and solids. Sensors 10:10663-10672.

Yost, W.A. (2014) Psychoacoustics and auditory perception. In: Perspectives on Auditory Research. Eds. Popper, A.N., Fay, R.R. Springer Science + Business Media, New York. pp. 611-631. 